\title{
METHOD OF SKETCH PROFILING WITH SPLINE CURVES FOR FOOTWEAR DESIGN
}

\section{Vladyslava SKIDAN ${ }^{1 *}$, Tetyana NADOPTA², Olena MYTELSKA ${ }^{1}$, Halyna YEFIMCHUK ${ }^{3}$, Iryna STETSIUK ${ }^{1}$, Anzhelika YANOVETS $^{3}$}

${ }^{1}$ Kyiv National University of Technology and Design, Nemyrovych-Danchenko Str., build.2, 01011 Kyiv, Ukraine, e-mail:

$$
\text { v.v_skidan@ukr.net }
$$

${ }^{2}$ Khmelnytsky National University, Ukraine

${ }^{3}$ Lutsk National Technical University, Ukraine

\section{METHOD OF SKETCH PROFILING WITH SPLINE CURVES FOR FOOTWEAR DESIGN}

ABSTRACT. The method of profiling sketches with spline curves with curvilinear guide paths is proposed in the work. The variants of possible combinations of types of spline sections are considered, all necessary variants of point positions for detection of a spline curve are given. The advantages of the developed method are the simplification of the design procedure of the proposed type of curves while providing more accurate representation of the real details, the mobility in controlling the shapes of curvilinear curves of sketch parts with a decrease in the order of the curve, including the curvature of different directions, which is in particular of first importance for all curves of the characteristic of shoe last sketches and conditional unfolding of the shoe last.

KEYWORDS: method of profiling, sketch, spline, designing, footwear

\section{METODĂ DE TRASARE A SCHIȚELOR UTILIZÂND CURBE SPLINE PENTRU PROIECTAREA ÎNCĂLTT̆MINTEI}

REZUMAT. În lucrare se propune o metodă de trasare a schițelor utilizând curbele spline cu traiectorii curbilinii. Sunt luate în considerare variante ale posibilelor combinații de tipuri de secțiuni spline și sunt date toate variantele necesare ale pozițiilor punctelor pentru detectarea unei curbe spline. Avantajele metodei dezvoltate sunt: simplificarea procedurii de proiectare a tipului de curbe propus oferind în același timp o reprezentare mai precisă a detaliilor reale, mobilitatea în controlul formelor curbelor de tip curbiliniar ale părților schiței cu o scădere în ordinea curbei, inclusiv curbarea în direcții diferite, care are o mare importanță pentru toate curbele specifice schiței calapodului și desfășurarea condițională a calapodului.

CUVINTE CHEIE: metodă de trasare, schiță, spline, proiectare, încălțăminte

\section{PROCÉDÉ DE TRACER LES CROQUIS AVEC DES COURBES SPLINES POUR LA CONCEPTION DE CHAUSSURES}

RÉSUMÉ. Dans cet article on propose un procédé de tracer les croquis avec des courbes splines avec des chemins de guidage curvilignes. Les variantes de combinaisons possibles de types de sections splines sont considérées et toutes les variantes de positions de point nécessaires à la détection d'une courbe spline sont indiquées. Les avantages de la méthode développée sont la simplification de la procédure de conception du type de courbes proposé, tout en fournissant une représentation plus précise des détails réels, la mobilité dans le contrôle des formes des courbes curvilignes des pièces du croquis avec une diminution de l'ordre des courbes, y compris la courbure des différentes directions, ce qui est notamment de première importance pour toutes les courbes caractéristiques pour les croquis de la forme des chaussures et du développement conditionnel de la forme.

MOTS-CLÉS : procédé de tracer, croquis, spline, conception, chaussures

\footnotetext{
* Correspondence to: Vladyslava SKIDAN, Kyiv National University of Technology and Design, Nemyrovych-Danchenko Str., build.2, 01011 Kyiv, Ukraine,e-mail:v.v_skidan@ukr.net
} 


\section{INTRODUCTION}

The necessary condition for increasing the efficiency of the organization of manufacturing and quality assurance of products of footwear industry is the introduction of innovative technologies, namely, the development of manufacturing, scientific, technical and innovation activities of enterprises using the latest achievements. The advancement of footwear industry is aimed at the development of the concept of footwear design automatisation, which provides a continuous connection of design processes, which include the development, the design, the implementation and use of footwear products.

Modern methods of application of applied and analytical geometry bases allow to simulate objects of rather complex forms and footwear products are among these objects. At the same time tasks that are being solved are directed on the search of analytical description and further modeling of objects using curves of different orders. Methods of simulating curves according to the way of their description can conditionally be divided into: using arrays of points; using equations. Firstly, the application of arrays of points is bulky, because it involves the use of significant numerical computational methods, and secondly, found in this way characteristics may not meet the requirements which had been set and do not contain an analytical basis [1]. They also do not solve the problem fully because they do not take into account the geometric characteristics appropriate to curves. There is also a certain number of methods for finding the dependences for curve equation descriptions in the form of various functions, polynomials, etc.

As it is known, the processes of modeling and designing products are largely associated with the creation and use of geometric models of surfaces or contours of surfaces. Objects with a complex curvilinear surface (foot, shoe last, shoe uppers), are of the greatest difficulty in designing because in order to ensure the appropriate quality of the products the structure of the foot should be taken into account.

Therefore, the creation of methods for processing the received source information of analytical modeling is an integral part of the research and shows the way for information footwear design.

\section{RESEARCH METHODS}

In the practice of design work for the simulation of curve lines certain approaches and methods are used [1-11]. The basis of these methods is the use of geometric techniques and the formation of a curves description model using complex mathematical techniques and transformations.

In works [12-14] the main principles of the use of spline curves for the design of sketches of details of footwear industry. Theoretical principles and algorithms for the solution of the inverse problem of a lineation design, which means to find the position of control points of the spline at known positions of points of sketch parts are presented there. The corresponding software for the practical realization of the inverse problem algorithms has been developed.

\section{RESEARCH RESULTS}

It is proposed to use Bezier spline curves to develop an analytical model. This spline category is most commonly used in automated design systems and in many graphical packages. The advantages of using these curves include the relatively simple mathematical apparatus, the description of bodies of any complexity with the necessary accuracy.

In the first instance, it is necessary to define some specific issues related to the classification and terminology of splines in general and splines with curvilinear guides in particular. Spline or spline curve is a smooth line, that is a line at any point which the derivative is determined monosemantically. A straight line (a first-order spline, defined by two control points i.e. the ends of this line) can be a spline in a specific case. Basically, the lineation of a part can have a lot of bends, but it should be borne in mind that each bend requires a separate control point, and the order of the curve per unit is greater than the number of these bends, respectively, the 
number of control points per unit is greater than the order of the curve.

In the article [14] it is shown that the use of splines with curvilinear guides can greatly complicate the shape of the curve without increasing its order. It is known [1] that the further a certain section from a certain control point is located, the less the position of this point affects the shape of this spline area.

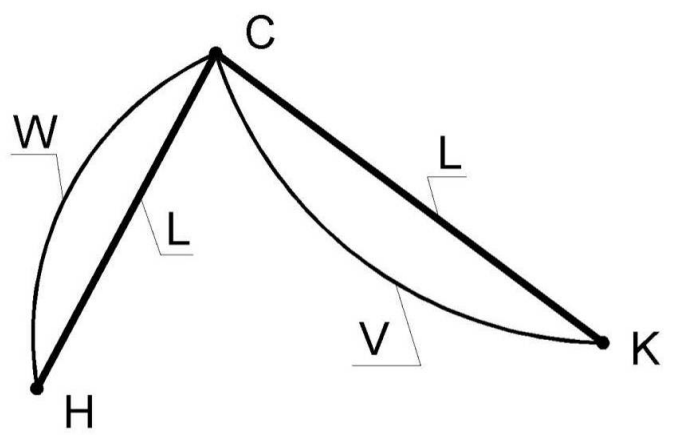

Figure 1. Scheme of symbols in the EU

So, from this point on, to simplify the presentation, it is enough to investigate the analyst of its element which is the simplest component of the spline curve. The spline element (EC) is considered to be the least complicated section (excluding the first order spline), which is a spline of the second order and is determined by three control points. We also conditionally set the sequence of these points by bypassing them clockwise (the direction for analytics has no principal importance), so the point $\mathrm{H}$ will be the point of the beginning of the $\mathrm{EC}$, the point $\mathrm{C}$ - the middle, and the point $\mathrm{K}$ - the final (Fig. 1). Accordingly, $\mathrm{HC}$ sections are called the initial section of the EC, and the segment CK - the final. Usual HC and CK splines are straight lines, which we denote by the letter $L$. The ordinary EC of $L$ type is inside the corner formed by the guides, and its ends coincide with the points of the beginning and the end of the $\mathrm{EC}$ ( $\mathrm{H}$ and $\mathrm{K}$ respectively) (these properties are reserved for $\mathrm{EC}$ of all types).

Curvilinear guidance $(\mathrm{KH})$ is any curve that connects the ends of the initial or final sections. The simplest of them can be circle arcs, ellipses etc. From this point on, curvilinear guides in the form of circle arches are under consideration. If the center of $\mathrm{KH}$ curvature is inside the angle formed by the EC guides, then this $\mathrm{KH}$ is called convex (type $\mathrm{W}$ ), if outwardly it is called curved one ( $V$ type). Obviously, the center of the circle will always be symmetric relatively to the ends of the corresponding section.

LL option has been considered in details from the standpoint of analytics in [1], and the construction principle in [5]. It should be noted that the basis for all calculations needed to construct splines of different types is the parameter $t$, because the oscillation of the position of any point on the segment is determined by multiplying this parameter by the length of the segment.

\section{WL Option}

In this combination the initial guide is curvilinear convex, the finite is rectilinear one. The calculation scheme is shown in Fig. 2.

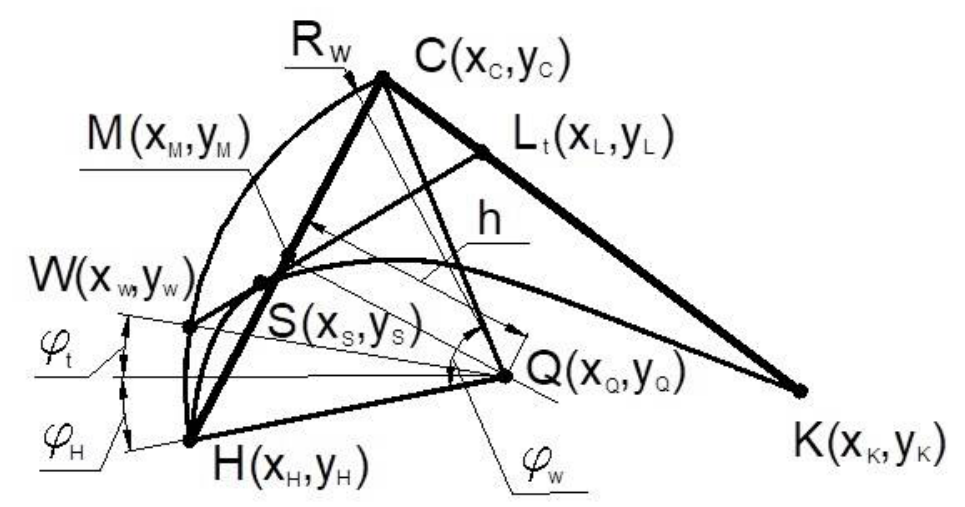

Figure 2. The scheme of construction of WL spline type 
The position of the control points of $H\left(x_{H}, y_{H}\right), C\left(x_{C}, y_{C}\right), K\left(x_{K}, y_{K}\right)$ spline is specified by the spline control points coordinates, the radius of the curvilinear guide $\mathrm{RW}$ is chosen selectively. The task is to determine the coordinates of the spline point at a certain value of the parameter $t$ (the current $S$ point with the coordinates $\left.\mathrm{x}_{\mathrm{s}}, \mathrm{y}_{\mathrm{s}}\right)$.

$$
\begin{aligned}
& x_{S}=x_{W}+t\left(x_{L}-x_{W}\right) . \\
& y_{S}=y_{W}+t\left(y_{L}-y_{W}\right) .
\end{aligned}
$$

Coordinates of $\mathrm{L}$ point

$x_{L}=x_{C}+t\left(x_{K}-x_{C}\right)$

$y_{L}=y_{C}-t\left(y_{C}-y_{K}\right)$

Coordinates of $\mathrm{W}$ point

$x_{W}=x_{Q}-R_{W} \cos \varphi_{t}$

$y_{W}=y_{Q}+R_{W} \sin \varphi_{t}$

The position of the center of the curvilinear guide circle is determined from the following construction. From the middle of $\mathrm{M}$ point of the initial segment $\mathrm{HC}$, which coordinates are

$$
\begin{aligned}
& x_{M}=x_{H}+0,5\left(x_{C}-x_{H}\right), \\
& y_{M}=y_{H}+0,5\left(y_{C}-y_{H}\right)
\end{aligned}
$$
set on it

a perpendicular is made, the distance is

$$
h=\sqrt{R^{2}-(0,5 H C)^{2}} \text {. }
$$

If we take into account that the angular coefficient of inclination of $\mathrm{HC}$ guide is

$k_{H C}=\left(y_{C}-y_{H}\right) /\left(x_{C}-x_{H}\right)$, then the perpendicular $k_{h}=-\left(1 / k_{H C}\right)$, which is numerically equal to the inclination angle tangent of the perpendicular. Then

$$
\begin{aligned}
& x_{Q}=x_{M}+h \cos \left(\operatorname{arctg} k_{h}\right), \\
& y_{Q}=y_{M}-h \sin \left(\operatorname{arctg} k_{h}\right)
\end{aligned} .
$$

Angle $\varphi_{t}$, which is required to determine the coordinates of the current point $\mathrm{W}\left(\mathrm{x}_{\mathrm{w}}, \mathrm{y}_{\mathrm{w}}\right)$,

$$
\varphi_{t}=t \cdot \varphi_{W}-\varphi_{H} \text {, }
$$

where the secondary angle is

$$
\varphi_{H}=\operatorname{arctg}\left(\left(y_{Q}-y_{H}\right) /\left(x_{Q}-x_{H}\right)\right)
$$

and the angle of the curvilinear guide is

$$
\begin{aligned}
& \varphi_{W}= 2(\arcsin (0,5 H C / R) . \\
& \text { Length of the segment } \\
& H C=\sqrt{\left(x_{C}-x_{H}\right)^{2}+\left(y_{C}-y_{H}\right)^{2}}
\end{aligned}
$$

The given analytics is the basis for automated calculations of coordinates of a spline curve points with a circular convex initial guideline.

Let's consider other options.

\section{VL Option}

In this case, the initial guide is a concave circular guide, the terminal guide is a straight guide. A scheme of such combination of guides is shown in Fig. 3. The system of symbols used in the previous scheme has been saved as much as possible.

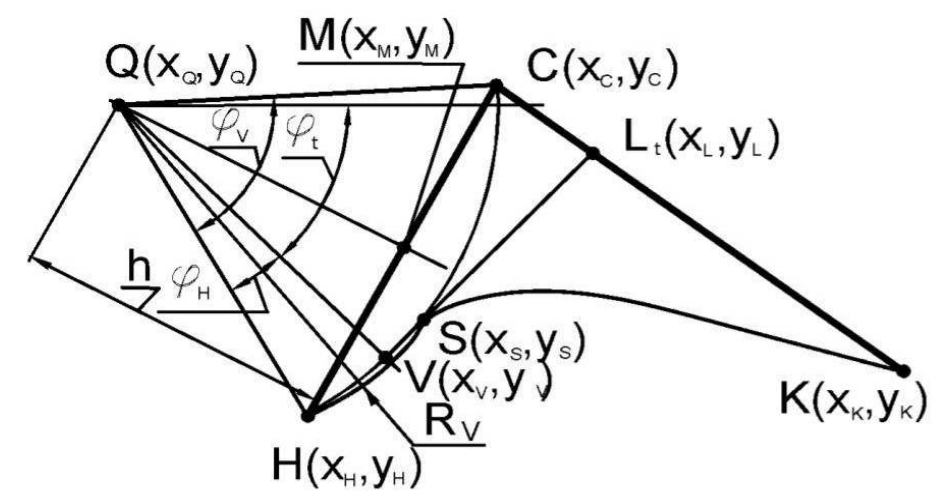

Figure 3. The scheme of construction of VL spline type 
The task is to determine the coordinates of the spline point at a certain value of the parameter $\mathrm{t}$ (the current point $\mathrm{S}$ with the coordinates $\left.\mathrm{x}_{\mathrm{s}}, \mathrm{y}_{\mathrm{s}}\right)$.

$$
\begin{aligned}
& x_{S}=x_{W}+t\left(x_{L}-x_{W}\right), \\
& y_{S}=y_{W}+t\left(y_{L}-y_{W}\right), \\
& x_{L}=x_{C}+t\left(x_{K}-x_{C}\right), \\
& y_{L}=y_{C}-t\left(y_{C}-y_{K}\right), \\
& x_{W}=x_{Q}+R_{W} \cos \varphi_{t}, \\
& y_{W}=y_{Q}-R_{W} \sin \varphi_{t} . \\
& x_{M}=x_{H}+0,5\left(x_{C}-x_{H}\right), \\
& y_{M}=y_{H}+0,5\left(y_{C}-y_{H}\right) \\
& h=\sqrt{R^{2}-(0,5 H C)^{2}} .
\end{aligned}
$$

Angular coefficient of the guide $\mathrm{HC}$ inclination
$k_{H C}=\left(y_{C}-y_{H}\right) /\left(x_{C}-x_{H}\right)$, then the perpendicular angle coefficient $k_{h}=-\left(1 / k_{H C}\right)$, which is numerically equal to the tangent of the angle of perpendicular inclination. Then

$$
\begin{aligned}
& x_{Q}=x_{M}+h \cos \left(\operatorname{arctg} k_{h}\right), \\
& y_{Q}=y_{M}+h \sin \left(\operatorname{arctg} k_{h}\right) . \\
& \varphi_{t}=\varphi_{W}-\varphi_{H}-\arcsin \left(\left(y_{C}-y_{Q}\right) /\left(x_{C}-x_{Q}\right)\right) . \\
& \varphi_{W}=2(\arcsin (0,5 H C / R) \\
& \varphi_{H}=t \cdot \varphi_{W}, \\
& \varphi_{W}=2(\arcsin (0,5 H C / R) . \\
& H C=\sqrt{\left(x_{C}-x_{H}\right)^{2}+\left(y_{C}-y_{H}\right)^{2}} .
\end{aligned}
$$

\section{WV Option}

The corresponding scheme of this combination is shown in Fig. 4.

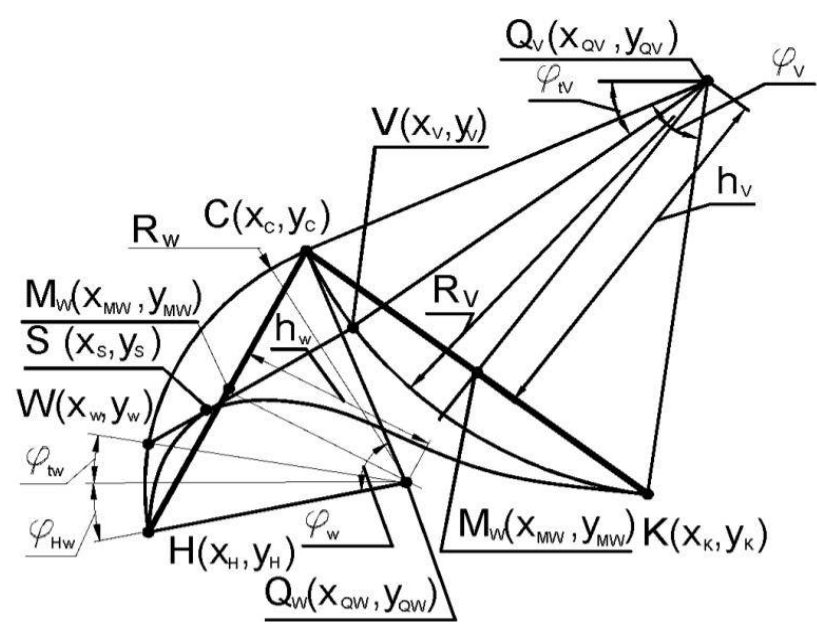

Figure 4. Scheme of spline construction of WV type

In fig. 4 the following indexing system is used: the parameters relating to the convex curvilinear direction include $\mathrm{W}$ index, concave - $V$ index. Parameters concerning the convex curvilinear direction are similar to analog analyst in Fig. 2 taking into account the specifics of the designations, the study material has been presented without comments and explanations.

$x_{W}=x_{Q W}-R_{W} \cos \varphi_{t W}$,

$$
\begin{aligned}
& y_{W}=y_{Q W}+R_{W} \sin \varphi_{t W} \\
& x_{M W}=x_{H}+0,5\left(x_{C}-x_{H}\right), \\
& y_{M W}=y_{H}+0,5\left(y_{C}-y_{H}\right) \\
& h_{W}=\sqrt{R_{W}^{2}-(0,5 H C)^{2}} . \\
& k_{H C}=\left(y_{C}-y_{H}\right) /\left(x_{C}-x_{H}\right), \\
& k_{h W}=-\left(1 / k_{H C}\right) \\
& x_{Q W}=x_{M W}+h_{W} \cos \left(\operatorname{arctg} k_{h W}\right),
\end{aligned}
$$


$y_{Q W}=y_{M W}-h_{W} \sin \left(\operatorname{arctg} k_{h W}\right)$.

$\varphi_{t}=t \cdot \varphi_{W}-\varphi_{H}$.

The angle $\varphi_{W}$ is determined by

$\varphi_{t W}=t \cdot \varphi_{W}-\varphi_{H W}$,

$\varphi_{H W}=\operatorname{arctg}\left(\left(y_{Q W}-y_{H}\right) /\left(x_{Q W}-x_{H}\right)\right)$,

$\varphi_{W}=2\left(\arcsin \left(0,5 H C / R_{W}\right)\right.$.

$H C=\sqrt{\left(x_{C}-x_{H}\right)^{2}+\left(y_{C}-y_{H}\right)^{2}}$.

$\checkmark$ point coordinates are determined in

the following way

$x_{V}=x_{Q V}-R_{V} \cos \varphi_{t V}$,

$y_{V}=y_{Q V}-R_{V} \sin \varphi_{t V}$

$x_{M V}=x_{C}+0,5\left(x_{K}-x_{C}\right)$,

$y_{M V}=y_{C}+0,5\left(y_{C}-y_{K}\right)$

$h_{V}=\sqrt{R_{V}^{2}-(0,5 K C)^{2}}$.

$k_{K C}=\left(y_{K}-y_{C}\right) /\left(x_{K}-x_{C}\right)$,

$k_{h V}=-\left(1 / k_{K C}\right)$

$x_{Q V}=x_{M V}+h_{V} \cos \left(\operatorname{arctg} k_{h V}\right)$,

$y_{Q V}=y_{M V}+h_{V} \sin \left(\operatorname{arctg} k_{h V}\right)$.

$\varphi_{t V}=t \cdot \varphi_{V}+\arcsin \left(\left(y_{Q V}-y_{C}\right) / R_{V}\right)$.

$\varphi_{V}=2\left(\arcsin \left(0,5 K C / R_{V}\right)\right.$.

$K C=\sqrt{\left(x_{C}-x_{K}\right)^{2}+\left(y_{C}-y_{K}\right)^{2}}$.

\section{Vw Option}

The variant scheme is shown in Fig. 5. Analytics to Fig. 5, as it was done previously for other schemes, is given without comments.

The coordinates of $V$ point are determined in the following way

$x_{V}=x_{Q V}+R_{V} \cos \varphi_{t V}$,

$y_{V}=y_{Q V}-R_{V} \sin \varphi_{t V}$

$x_{M V}=x_{C}-0,5\left(x_{K}-x_{H}\right)$,

$y_{M V}=y_{C}-0,5\left(y_{C}-y_{H}\right)$

$h_{V}=\sqrt{R_{V}^{2}-(0,5 H C)^{2}}$.

$k_{K C}=\left(y_{C}-y_{H}\right) /\left(x_{C}-x_{H}\right)$,

$k_{h V}=-\left(1 / k_{K C}\right)$.

$x_{Q V}=x_{M V}-h_{V} \cos \left(\operatorname{arctg} k_{h V}\right)$,

$y_{Q V}=y_{M V}+h_{V} \sin \left(\operatorname{arctg} k_{h V}\right)$.

$\varphi_{t V}=\varphi_{V}-t \cdot \varphi_{V}-\arcsin \left(\left(y_{C}-y_{Q V}\right) / R_{V}\right.$

$\varphi_{V}=2\left(\arcsin \left(0,5 H C / R_{V}\right)\right.$.

$H C=\sqrt{\left(x_{C}-x_{H}\right)^{2}+\left(y_{C}-y_{H}\right)^{2}}$.

$x_{W}=x_{Q W}+R_{W} \cos \varphi_{t W}$

$y_{W}=y_{Q W}+R_{W} \sin \varphi_{t W}$.

$x_{M W}=x_{K}+0,5\left(x_{K}-x_{C}\right)$,

$y_{M W}=y_{K}+0,5\left(y_{C}-y_{K}\right)$.

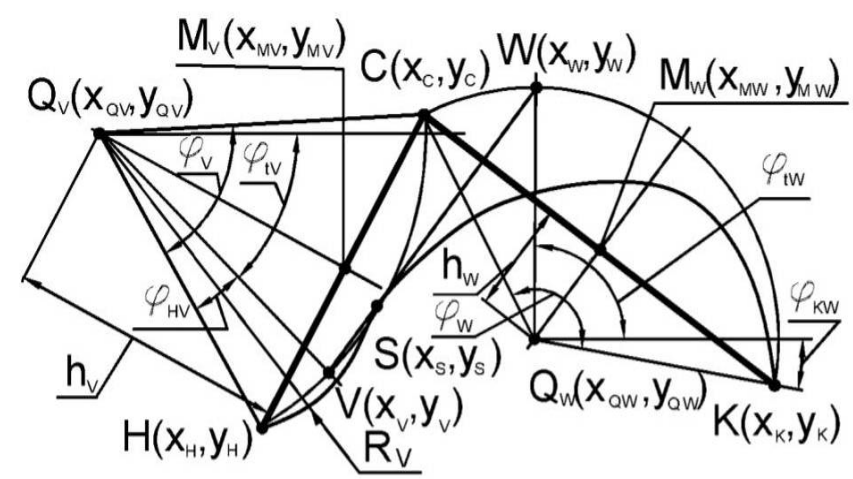

Figure 5 . The scheme of construction of VW spline type

$$
\begin{aligned}
& h_{W}=\sqrt{R_{W}^{2}-(0,5 K C)^{2}} . \\
& k_{H C}=\left(y_{C}-y_{K}\right) /\left(x_{C}-x_{K}\right),
\end{aligned}
$$$$
k_{h W}=-\left(1 / k_{H C}\right) \text {. }
$$$$
x_{Q W}=x_{M W}-h_{W} \cos \left(\operatorname{arctg} k_{h W}\right) \text {, }
$$ 
$y_{Q W}=y_{M W}-h_{W} \sin \left(\operatorname{arctg} k_{h W}\right)$.

$\varphi_{W}$ angle is determined in the following way

$\varphi_{W}=2\left(\arcsin \left(0,5 \mathrm{KC} / R_{W}\right)\right.$

$\varphi_{t W}=\varphi_{W}-t \cdot \varphi_{W}-\varphi_{K W}$,

$\varphi_{K W}=\operatorname{arctg}\left(\left(y_{Q W}-y_{K}\right) /\left(x_{Q W}-x_{K}\right)\right)$,

$K C=\sqrt{\left(x_{C}-x_{K}\right)^{2}+\left(y_{C}-y_{K}\right)^{2}}$.

All other possible combinations (LW, LV, WW, VV, etc.) are individual cases of the above mentioned and the analyst for them can be developed based on the one given above.

It should be noted that in each of the drawings, despite the same position of control points, the shape of the spline is changing constantly, which one more time shows the advantages of splines with curved guides, the main advantage is the more flexible fitting of real lineation of parts. Another important fact to be taken into account is that the radius of the circular curvilinear guide should be greater than half of the length of the corresponding straight guide.

Profiling of parts of the lineations was done, using spline curves with curvilinear guides. The spline curve (for example, of the second order) is given by three points: apart from starting PS $\left(x_{S}, y_{S}\right)$ points and $P E\left(x_{E}, y_{E}\right)$ ending points an intermediate point $P_{1}\left(X_{P 1}\right.$, $\left.y_{P 1}\right)$, is required and while these points are connected by straight guides (Fig. 6).

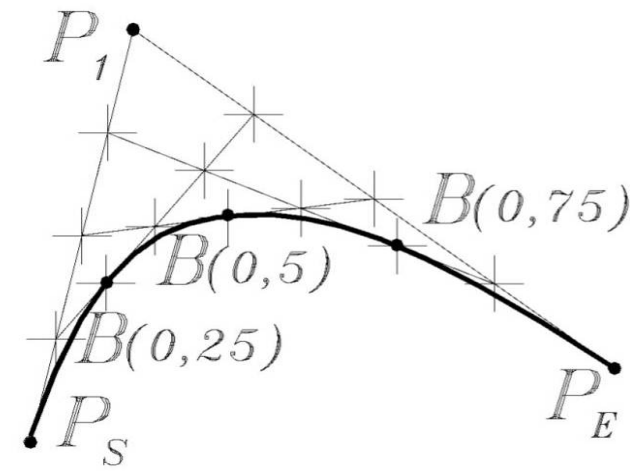

Figure 6. Formation of a spline curve with straight guides

On each sections of the guides additional points 1 (on the $P_{s}-P_{1}$ section) and 2 (section $\mathrm{P}_{1}-\mathrm{P}_{\mathrm{E}}$ ) are moving synchronously. At any time the distance to points 1 and 2 from the beginning of the corresponding section is determined as the product of the parameter $t$ (this is the parameter (time-iterator) which varies within $0 \ldots 1$, assuming that $t_{i}=1$ when $i=1$ and $t=0$ when $i=0$ ) and its length. The point $B(t)$ is on the segment which connects points 1 and 2 whereas its distance from point 1 is also determined as the product of the parameter $t$ and the length of the segment 1-2. In Fig. 6. in order to simplify its perception, the construction of a spline curve is shown on the example of only a few points with values of the parameter $t 0 ; 0.25 ; 0.5 ; 0.75 ; 1$. However, the drawback of this method is the onevaluedness of the curve shape and the need of large number of control points for the complex curvatures of the lineations since straight-line guides are used for the control system. One more possible option for construction of complex sketches is to make use individual Bezier curves which can be sequentially connected with one another in Bezier spline. In order to ensure the smoothness of the line at the junction of two curves, the adjacent points of both curves must lie on the same line, which requires additional operations.

Taking into account the abovementioned imperfections, it is proposed to perform profiling of parts of the lineations using spline curves with curvilinear guides.

Fig. 7. shows the variant of construction of the sketch curve with the use of a curvilinear guide in the form of an arc of a circle between the points $P_{\mathrm{s}}-P_{1}$, and Fig. 8 . shows the variant of construction of the sketch curve with the additional use of the guide in the form of the arc of the circle $P_{1}-P_{E}$, with the opposite sign of curvature. Further construction is made following the abovementioned principles. 


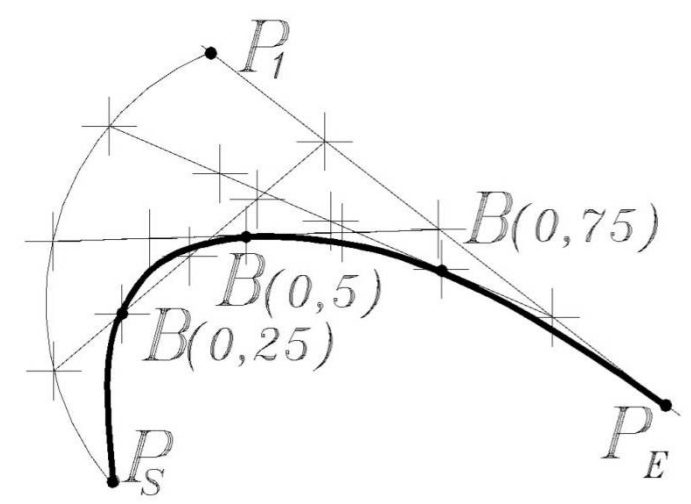

Figure 7. Construction of a spline curve with curvilinear guides

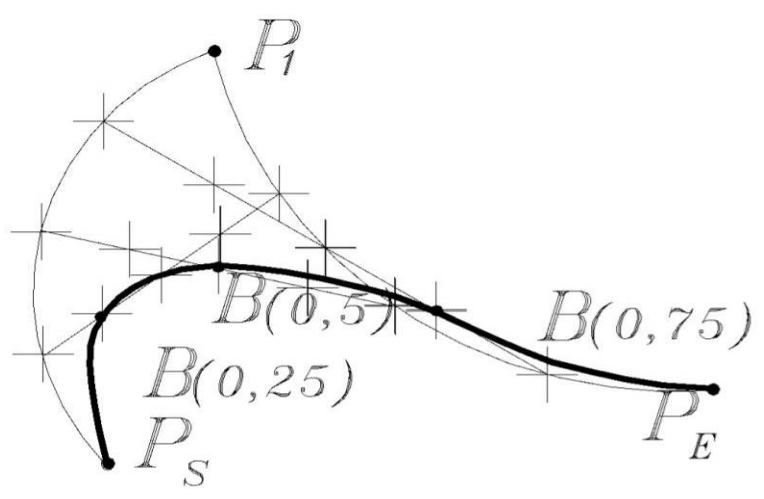

Figure 8. Construction of a spline curve with curvilinear guides (two arcs)
The given examples allow to obtain the curves of lineations of any form with the same control points $\mathrm{P}_{\mathrm{S}^{\prime}}, \mathrm{P}_{1}, \mathrm{P}_{\mathrm{E}}$.

An extremely important advantage of the method of constructing curves of the sketches is that the curve in Fig. 7 if it had been built using straight-line guides could be obtained only with the third order of the spline curve, the curve in Fig. 8 - the fourth, respectively it would require four and five control points, which would greatly complicate the construction process. It should also be mentioned that the shape of the curvilinear guide can be omniform which also increases the polyvariability of the spline curves.

Thus, presented examples demonstrate the advantages of using curvilinear guides which simplify the construction of complex sketches.

The presented properties and principles of construction of spline curves allow to solve the inverse problem of profiling the contours of the longitudinally vertical section of the inner mold line tool (Fig. 9), namely, at given points, where it is necessary to pass the curve through, to determine the exact position of the coordinates (saying more accurately to determine the matrix

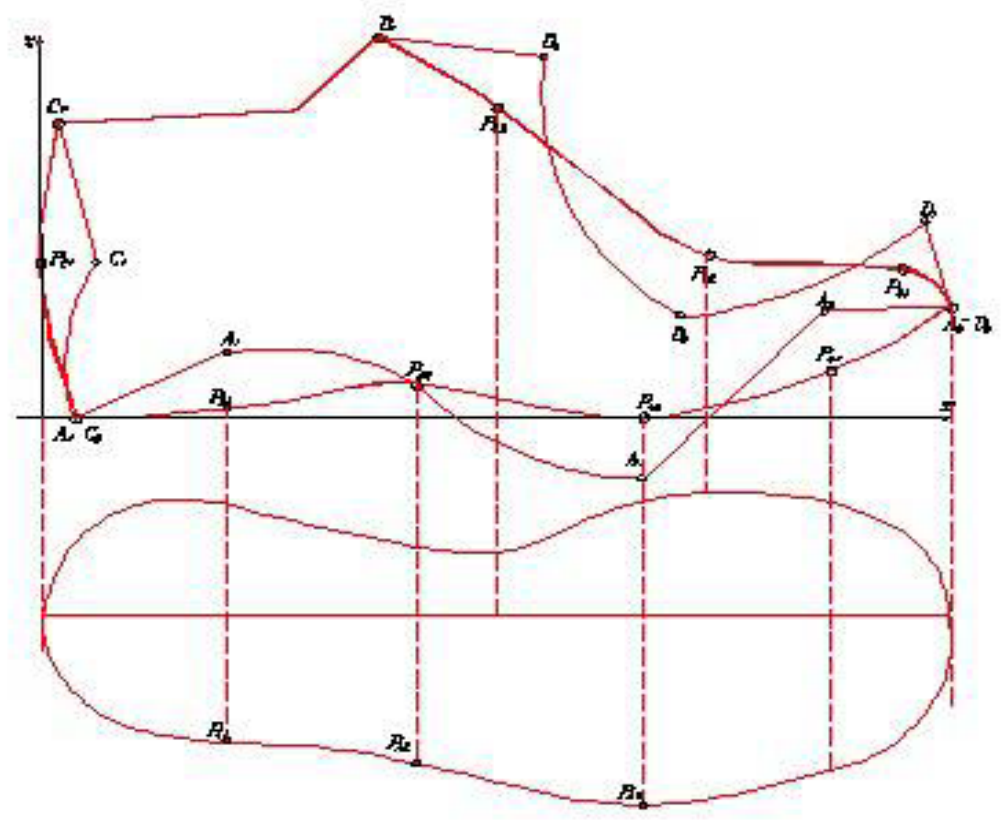

Figure 9. Principle of construction of the main contours of the longitudinal and vertical section of the inner mold line tool of shoes 
of coordinates) of the control points, which allows to describe the curves analytically which are assumed to be used to form contours with.

The mathematical apparatus of spline curves allows to reproduce a function with a predetermined accuracy (within 5\% for footwear industry) deviation from the original curve.

\section{CONCLUSIONS}

The method of profiling parts of sketches with spline curves with curvilinear guides has been proposed, which provides the flexibility of control of the shape of the curvilinear sections of the parts, reducing the order of the curve of considerable complexity, including the curvature of a different sign.

The analytical bases of determination of coordinates of spline curve points with circular curvilinear guides for the basic combinations of section types have been developed.

Profiling of sketch contours of the longitudinally vertical cut of the inner mold line tool of shoe using spline curves with curvilinear guides has been proposed.

\section{REFERENCES}

1. Nadopta, T., Development of the Method of Designing Parts of the Top of Shoes on the Basis of the Prototype Analytical Model, Candidate of Technical Sciences Thesis (in Ukrainian), Khmelnytsky National University, 2013, 214.

2. Kalashnikov, O., Geometric and Computer Simulation of the Equipment of Special Rapid Reaction, Candidate of Technical Sciences Thesis (in Ukrainian), Tavriya State Agrotechnical Academy, 2005, 45.

3. Belkyn, E., Modular Geometric Method of Mathematical Modeling of a Frame-like Discrete Definite Surface (in Russian), Izvestiya Tul'GU, Technological System Engineering Series, 2006, 99-110.
4. Tkachevskyj, Y., Using Structural Geometric Models for Aircraft Shape Control, Applied Geometry and Engineering Graphics (in Ukrainian), KNUBA, 2005, 179-182.

5. Malkina, V., Geometrical Modeling of Surfaces on the Basis of Special Systems of Orthonormal Polynomials (in Ukrainian), Abstract for Candidate of Technical Sciences Thesis, KNUBA, 1999, 16.

6. Driscu, M., A method to approximate a spatial surface using a Bezier bi-cubic surface, "Gh. Asachi" Technical University, Leather and Footwear Journal, 2010, 10, 2, 10-32.

7. Prautzsch, H., Boehm, W., Bézier and B-Spline Techniques Cheapest Online, 1995, Hartmut Springer Verlag.

8. Cinque, L., Levialdi, S., Malizia, A., Shape description using cubic polynomial Bézier curves, Pattern Recog Lett, 1998, 19, 821-828, https://doi.org/10.1016/S01678655(98)00069-5.

9.Pala,S., Gangulyb, P.,CubicBézierapproximation of a digitized curve, 2007, Pattern Recog Lett, 2007, 40, 2730-2741, https://doi. org/10.1016/j.patcog.2007.01.019.

10. Drişcu, M., Mihai, A., CAD procedure for patterns with Bézier curves, Textile Industry, 2009, 5.

11. Chang, H.H., Yan, H., Vectorization of handdrawn image using piecewise cubic Bézier curves fitting, Pattern Recog Lett, 1998, 31, 1747-1755, https://doi.org/10.1016/S00313203(98)00045-4.

12. Nadopta, T., Sketch Profile Modeling of Shoes Prototype Using Bezier Curves (in Ukrainian), Bulletin of the Khmelnytsky National University, vol 6, 2008, 222-226.

13. Nadopta, T., Features of Dimensional Prototype Trace Formation (in Ukrainian), Bulletin of Khmelnitsky National University, vol 4, 2010, 247-252. 
14. Skidan, O., Nadopta T., Pastukh I., Theoretical Background of Analytical Shoe Design (in Ukrainian), Bulletin of Khmelnytsky National University, vol 4, 2015, 244-249.
(C) 2019 by the author(s). Published by INCDTPICPI, Bucharest, RO. This is an open access article distributed under the terms and conditions of the Creative Commons Attribution license (http:// creativecommons.org/licenses/by/4.0/). 